\title{
Rapid and Efficient Uncatalyzed Knoevenagel Condensations from Binary Mixture of Ethanol and Water
}

\author{
João M. G. O. Ferreira, ${ }^{a}$ João B. M. de Resende Filho, ${ }^{b}$ Poliane K. Batista, ${ }^{a}$ \\ Ercules E. S. Teotonio ${ }^{*, a}$ and Juliana A. Vale Va, $^{*}$ \\ ${ }^{a}$ Departamento de Química, Universidade Federal da Paraíba, 58051-970 João Pessoa-PB, Brazil \\ ${ }^{b}$ Instituto Federal de Educação, Ciência e Tecnologia da Paraíba, 58800-970 Sousa-PB, Brazil
}

\begin{abstract}
This paper presents a new green protocol for Knoevenagel condensations of aldehydes and compounds with an active methylene group in a binary mixture of ethanol/water (3:7, v/v). This medium favored the uncatalyzed Knoevenagel reactions and easy workup products can be obtained by precipitation in this medium and showed good isolated yields $(55-100 \%)$ in short reaction times (1-60 $\mathrm{min})$.
\end{abstract}

Keywords: Knoevenagel condensation, ethanol/water, green approach, binary mixture, active methylene compounds and aldehydes

\section{Introduction}

The Knoevenagel condensation is an aldol reaction between carbonylated substances (such as ketones and aldehydes $)$ and active methylene compounds $\left(-\mathrm{CH}_{2}-\right.$ attached to two electron withdrawing groups, EWGs) producing alkenes. ${ }^{1-3} \mathrm{It}$ is one of the most useful reactions to form $\mathrm{C}-\mathrm{C}$ bonds, generally used to assist the synthesis of several compounds with biological relevance ${ }^{4}$ and other possible applications, such as drugs, ${ }^{5-10}$ natural products, ${ }^{11,12}$ and polymers. ${ }^{13-15}$

Weak bases, such as amines and basic salts, usually catalyze these reactions. ${ }^{1-3}$ The base furthers the deprotonation of the active methylene compound to create a carbanion, which, in turn, attacks the carbonyl. In the earliest works, the amines used to catalyze the reactions presented a considerable level of toxicity. ${ }^{16,17}$ Thus, many papers have been published in recent years concerning proposals for ecofriendly reaction conditions, ${ }^{18-22}$ in accordance with the principles of green chemistry. ${ }^{22-25}$

From this perspective, many researchers have developed new catalysts involving the mentioned principles. One such type, which have received great attention, are the heterogenized catalysts. ${ }^{26-28}$ They present certain advantages compared with their respective homogeneous compounds, such as facile separation methods (filtration, magnetic

*e-mail: ercteot@gmail.com; julianadqf@yahoo.com.br separation, etc.) for recovery of the catalyst, easier reuse, stability at high temperatures and pressures, and relatively low toxicity. Some of these reactions even occur without solvents, decreasing the toxicity of the reaction medium. ${ }^{29-31}$ Furthermore, other researchers ${ }^{32-34}$ have reported solventcatalyzed Knoevenagel condensations, generally using ionic liquids or water (green solvents), under different conditions.

In our studies, we noted that Knoevenagel condensations were faster in ethanol than in other solvents (apolar or polar, protic or aprotic). Many papers have reported this reaction in ethanol using catalysts, ${ }^{35,36}$ but none have discussed this reaction uncatalyzed in ethanol until this report. In addition, the uncatalyzed Knoevenagel condensations reported in the literature generally use water ${ }^{37,38}$ or ionic liquids $^{39-41}$ as solvents. Thus, this work presents a new green approach for the quick and efficient uncatalyzed Knoevenagel condensation of different substrates in a mixture of ethanol/water.

\section{Experimental}

Reagents and instruments

The solvents, aldehydes, ketones and active methylene group compounds (malononitrile and indan-1,3-dione) were obtained from Sigma-Aldrich Co. Ethanol (200 proof) was purchased from Tedia. The ethanol/water mixtures 
were prepared in volumetric proportions (1:9, 1:1, 3:7, $7: 3, \mathrm{v} / \mathrm{v})$. All chemicals were employed without further purification.

\section{General procedures for Knoevenagel condensations}

The aldehyde $(0.2 \mathrm{mmol})$ and the compound with the active methylene group $(0.2 \mathrm{mmol})$ were added to a test tube followed by the addition of the solvent (ethanol/ water $3: 7,0.8 \mathrm{~mL}$ ). The system was maintained at $80^{\circ} \mathrm{C}$ and magnetically stirred until the reaction completed. The reaction progress was monitored by thin layer chromatography (TLC). The products were obtained by precipitation with cooled water or by extraction with ethyl acetate. The extract was purified by column chromatography. All the products were characterized by Fourier transform infrared spectroscopy (FTIR), gas-chromatography mass spectrometry (GC-MS), ${ }^{1} \mathrm{H}$ and ${ }^{13} \mathrm{C}$ nuclear magnetic resonance (NMR).

\section{Results and Discussion}

To examine the effects of the different solvents in uncatalyzed Knoevenagel condensations it was tested a standard reaction between benzaldehyde and malononitrile in solvent-free conditions and in aprotic polar, protic polar and apolar solvents (Table 1).

As seen in Table 1, the reaction times in toluene (entry 2, apolar solvent) and tetrahydrofuran (thf, entry 3, aprotic polar solvent) were the slowest. These results are in agreement with the mechanism of these amine-free reactions. ${ }^{42}$ This mechanism is well known to involve carbanion formation and an ionic intermediate (enolate). Therefore, the reaction in a polar solvent (thf, for example) would be expected to be faster than in an apolar solvent (toluene, for example). When this reaction was carried out under solvent-free conditions (entry 1 ), the reaction time was even faster than those mentioned above.

The reactions in protic polar solvents (entries 4-15, water and alcohols) were considerably faster than in the aprotic polar and apolar solvents. The reaction times increased when long carbon chain alcohols were used as solvents (entries 5, 7, 9-14). In water (entry 4), the reaction was completed at the same time $(60 \mathrm{~min})$ as the reactions in methanol (entry 5) and ethanol (entry 7) high-performance liquid chromatography (HPLC) grade (anhydrous). However, when using ethanol $95 \%$ or methanol $99.9 \%$, the reaction time surprisingly decreased to $30 \mathrm{~min}$ (half the time). This event promoted our curiosity for the study of this reaction in the mixtures of ethanol/water (entries 15-18). As can be observed in
Table 1. The effect of solvents on Knoevenagel condensation of benzaldehyde and malononitrile ${ }^{\mathrm{a}}$

\begin{tabular}{|c|c|c|}
\hline entry & Solvent & time $^{b} / \min$ \\
\hline 1 & - & 540 \\
\hline 2 & toluene & 2880 \\
\hline 3 & thf $^{\mathrm{c}}$ & 2160 \\
\hline 4 & $\mathrm{H}_{2} \mathrm{O}$ & 60 \\
\hline 5 & $\mathrm{MeOH}^{\mathrm{c}, \mathrm{d}}$ & 60 \\
\hline 6 & $\mathrm{MeOH} 99.9 \%^{\mathrm{c}}$ & 30 \\
\hline 7 & $\mathrm{EtOH}^{\mathrm{d}}$ & 60 \\
\hline 8 & $\mathrm{EtOH} 95 \% \mathrm{c}$ & 30 \\
\hline 9 & propanol & 90 \\
\hline 10 & isopropanol & 60 \\
\hline 11 & butanol & 150 \\
\hline 12 & tert-butanol & 540 \\
\hline 13 & cyclohexanol & 360 \\
\hline 14 & octanol & 360 \\
\hline 15 & $\mathrm{EtOH}: \mathrm{H}_{2} \mathrm{O}(7: 3, \mathrm{v} / \mathrm{v})$ & 10 \\
\hline 16 & $\mathrm{EtOH}: \mathrm{H}_{2} \mathrm{O}(1: 1, \mathrm{v} / \mathrm{v})$ & 6 \\
\hline 17 & $\mathrm{EtOH}: \mathrm{H}_{2} \mathrm{O}(3: 7, \mathrm{v} / \mathrm{v})$ & 4 \\
\hline 18 & $\mathrm{EtOH}: \mathrm{H}_{2} \mathrm{O}(1: 9, \mathrm{v} / \mathrm{v})$ & 4 \\
\hline
\end{tabular}

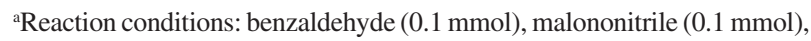
$0.4 \mathrm{~mL}$ of solvent, $75^{\circ} \mathrm{C}$; b the reactions were monitored by TLC; reflux temperature: $65^{\circ} \mathrm{C}$; ${ }^{\mathrm{d}} \mathrm{HPLC}$ grade.

the Table 1, when the mixture of ethanol/water presents a small volume of ethanol the reaction occurs faster than the one with the largest volume of ethanol. The same reaction in water (entry 4) or anhydrous ethanol (entry 7) is considerable slower than any mixture of ethanol/water. The mixture ethanol/water 3:7 v/v showed the best results (entry 17) and it was used as a solvent in subsequent reactions.

In addition, the reaction between benzaldehyde and malononitrile in ethanol/water, 3:7 v/v, was carried out at room temperature and under ultrasound conditions (both $150 \mathrm{~min}$ ). However, these reactions were slower than those carried out with heating at $75^{\circ} \mathrm{C}$.

The ethanol-water mixture presents particular properties compared with the isolated solvents that further the Knoevenagel condensation when performed in the mixed system: ( $i)$ a higher solvation power because of the formation of molecular chains interacting by hydrogen bonds (cluster formation); (ii) the lower dielectric constant of these mixtures when compared with the pure solvents 
Table 2. Knoevenagel condensations of benzaldehyde and different active methylene compounds in ethanol/water $3: 7(\mathrm{v} / \mathrm{v})^{\mathrm{a}}$

$\frac{\begin{array}{c}\text { Active methylene } \\ \text { compound }\end{array}}{\text { entry }}$

(1)

2<smiles>O=C1CC(=O)c2ccccc21</smiles>

(2)<smiles>CCOC(=O)CC#N</smiles>
16

(3)

4

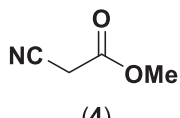

(4) and bis adduct was obtained. Interestingly, the reactions with Meldrum's acid in the mixture ethanol/water were a selective reactions giving only the Knoevenagel product and no trace of bis adduct was detected.

After the optimization of the conditions for the Knoevenagel condensations, several aldehydes were reacted with malononitrile (active methylene compound) in the selected conditions (Table 3).

In general, the reactions showed good isolated yields in short times (Table 3). The standard reaction with benzaldehyde and malononitrile (entry 1) was completed in 4 min (yield 82\%). The reaction with 4- $\mathrm{NO}_{2}$-benzaldehyde (entry 2) was faster than mentioned above due to the presence of the strong electron withdrawing group $\left(\mathrm{NO}_{2}\right)$ at the 4-position. In addition, the reactions with an electron donating group (entries 4 and 5) at the 4-position were slower than those with an electron withdrawing group at the same position.

The aldehydes with substituents (electron donating or withdrawing group) in the 3-position (entries 6 and 7) and 2-position (entries 8 and 9) exhibited behavior similar to reactions with those substituents at the 4-position. In addition, considerable steric hindrance was observed in the substrates with groups at the 2-position. The reactions with di-substituted aldehydes (entries 10-12) finished in 25-45 min and showed good yields. Surprisingly, the reaction time was very low for the tri-substituted aldehyde, compound $\mathbf{1 7}$ (entry 13), reacting completely in only $3 \mathrm{~min}$, with isolated yield of $99 \%$.

The reactions with heteroaromatic aldehydes (entries 20,22) finished in a short time. As the $\mathrm{n}$-pyridinecarboxyaldehydes $(\mathrm{n}=3$ or 4 , entries 20 , 21) are rather reactive electrophiles and are completely miscible in water, the reactions with these substrates were incredibly fast (in seconds). The aliphatic aldehyde (entry 19) completed at a time close to the substituted aromatic aldehydes.

These products were easily obtained by precipitation with the addition of cooled water and any purification process was used. However, in the cases that the product are soluble in the mixture of ethanol/water, it was obtained by extraction with ethyl acetate and after purified by chromatographic column.

The Knoevenagel condensation of ketones and malononitrile in the mixture of ethanol/water 3:7 $(\mathrm{v} / \mathrm{v})$ was initially verified and presented good results. The reactions between 4-methylcyclohexanone or 3-methylcyclohexanone and malononitrile, for example, finished in five and six hours, respectively, with $75 \%$ isolated yield for both. The study of these reactions (with ketones) in this mixture is still in progress. 
Table 3. Knoevenagel condensations of aldehydes and malononitrile in ethanol/water 3:7 (v/v) ${ }^{\mathrm{a}}$

\begin{tabular}{|c|c|c|c|c|}
\hline entry & Product & $\begin{array}{c}\operatorname{time}^{\mathrm{b}} / \\
\min \end{array}$ & $\begin{array}{c}\text { Isolated } \\
\text { yield / \% }\end{array}$ & $\begin{array}{c}\text { time } \\
(\text { yield } / \%)^{\mathrm{c}} \\
\min \end{array}$ \\
\hline
\end{tabular}

(5)

2<smiles>N#CC(C#N)=Cc1ccc([N+](=O)[O-])cc1</smiles>

(6)

3<smiles>N#CC(C#N)=Cc1ccc(Cl)cc1</smiles>

(7)

4<smiles>COc1ccc(C=C(C#N)C#N)cc1</smiles>

(8)

5<smiles>CN(C)c1ccc(C=C(C#N)C#N)cc1</smiles>

(9)

6<smiles>N#CC(C#N)=Cc1cccc([N+](=O)[O-])c1</smiles>

(10)

7<smiles>COc1cccc(C=C(C#N)C#N)c1</smiles>

(11)

8<smiles>N#CC(C#N)=Cc1ccccc1[N+](=O)[O-]</smiles>

(12)

9<smiles>COc1ccccc1C=C(C)C#N</smiles>

(13)

10<smiles>Cc1c(F)cccc1C=C(C#N)C#N</smiles>

(14)

11<smiles>COc1ccc(C=C(C#N)C#N)c(OC)c1</smiles>

60

3

25

$84^{\mathrm{d}} \quad 30(94)^{48}$

$85^{\mathrm{d}} \quad 60(91)^{48}$

50

$94^{\mathrm{d}}$

25

$72^{\mathrm{e}}$

$50(93)^{50}$

40

$75^{\mathrm{d}}$

$90(92)^{51}$

$94^{\mathrm{e}}$

$10(92)^{49}$

50

$80^{\mathrm{d}} \quad 15(90)^{52}$

$92^{\mathrm{e}}$

15

entry Product $\begin{gathered}\text { time }^{\mathrm{b}} / \\ \mathrm{min}\end{gathered}$

(16)

13<smiles>COc1cc(C=C(C#N)C#N)cc(OC)c1O</smiles>

(17)<smiles>N#CC(C#N)=Cc1cccc2ccccc12</smiles>

$20 \quad 89^{\mathrm{d}} \quad 40(92)^{53}$

(18)<smiles>N#CC(C#N)=Cc1ccc2ccccc2c1</smiles>

30

$95^{\mathrm{d}}$

$30(99)^{26}$

(19)<smiles>N#CC(C#N)=Cc1ccco1</smiles>

$15 \quad 75^{\mathrm{e}} \quad 30(92)^{54}$

(20)<smiles>N#CC(C#N)=Cc1cccs1</smiles>

$15 \quad 55^{\mathrm{d}} \quad 30(94)^{54}$

(21)<smiles>N#CC(C#N)=Cc1ccc2c(c1)OCO2</smiles>

(22)
20

21

19<smiles>CCCCCCC=C(C#N)C#N</smiles>

(23)<smiles>N#CC(C#N)=Cc1cccnc1</smiles>

(24)<smiles>N#CC(C#N)=Cc1ccncc1</smiles>

(25)
$10 \quad 100^{\mathrm{d}} \quad 20(94)^{55}$

$30 \quad 76^{\mathrm{e}} \quad 30(72)^{56}$ $1 \quad 92^{\mathrm{e}} \quad 3(86)^{57}$

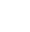

$1 \quad 91^{\mathrm{e}} \quad 30(95)^{58}$

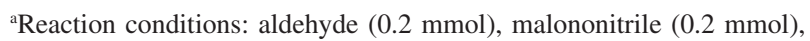

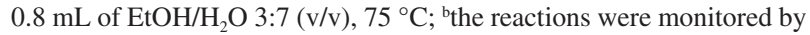

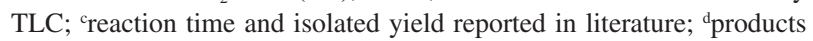
obtained by precipitation and washing with cooled water; ${ }^{e}$ products obtained by extraction and purified by chromatographic column. 


\section{Conclusions}

The mixture of ethanol/water 3:7 (v/v) was used as a solvent for uncatalyzed Knoevenagel condensation reactions and showed surprisingly excellent results (good yields, 55-100\%, and excellent times, 1-60 min) when compared with these reactions in ethanol or water. In recent decades, many works have reported syntheses of new molecules that used the Knoevenagel condensation in at least one step. Therefore, the development of new protocols is important to provide new ecofriendly methods for organic synthesis. The mixture of ethanol/water 3:7 (v/v) is an ecofriendly solvent, and many products of Knoevenagel condensations of aldehydes and compounds with an active methylene can be obtained by precipitation in this medium. This green protocol can provide the synthesis of new molecules from the Knoevenagel condensation or new ways to re-synthesize known molecules.

\section{Supplementary Information}

Supplementary data are available free of charge at http://jbcs.sbq.org.br as PDF file.

\section{Acknowledgments}

Tha authors thank CAPES and CNPq for financial support and Unical (Unidade da Central Analítica) of the IPeFarM-UFPB (Instituto de Pesquisa em Fármacos e Medicamentos da UFPB) for assistance with the NMR analysis.

\section{References}

1. Knoevenagel, E.; Ber. Dtsch. Chem. Ges. 1894, 27, 2345.

2. Knoevenagel, E.; Ber. Dtsch. Chem. Ges. 1896, 29, 172.

3. Jones, G.; Org. React. 1967, 15, 204.

4. Lavanya, G.; Padmavathi, V.; Padmaja, A.; J. Braz. Chem. Soc. 2014, 25, 1200 .

5. Zhang, J.; Li, W. L.; Wu, L. Q.; J. Braz. Chem. Soc. 2011, 22, 1236.

6. Beutler, U.; Fuenfschilling, P. C.; Steinkemper, A.; Org. Process Res. Dev. 2007, 11, 341.

7. Reddy, N. S.; Mallireddigari, M. R.; Cosenza, S.; Gumireddy, K.; Bell, S. C.; Reddy, E. P.; Reddy, M. R.; Bioorg. Med. Chem. Lett. 2004, 14, 4093.

8. Gupta, J. K.; Sharma, P. K.; Dudhe, R.; Chaudhary, A.; Singh, A.; Verma, P. K.; Mondal, S. C.; Yadav, R. K.; Kashyap, S.; Med. Chem. Res. 2012, 21, 1625.

9. Patel, R. V.; Kumari, P.; Rajani, D. P.; Chikhalia, K. H.; Med. Chem. Res. 2013, 22, 195.
10. Kaminskyy, D.; Den Hartog, G. J. M.; Wojtyra, M.; Lelyukh, M.; Gzella, A.; Bast, A.; Lesyk, R.; Eur. J. Med. Chem. 2016, 112,180 .

11. Tan, H.; Chen, X.; Chen, H.; Liu, H.; Qiu, S.; Eur. J. Org. Chem. 2015, 2015, 4956.

12. Lashkari, M.; Maghsoodlou, M. T.; Hazeri, N.; HabibiKhorassani, S. M.; Akbarzadeh Torbati, N.; García-Granda, S.; Torre-Fernández, L.; J. Heterocycl. Chem. 2015, 52, 873.

13. Kwak, G.; Fujiki, M.; Macromolecules 2004, 37, 2021.

14. Birzan, L.; Cristea, M.; Draghici, C. C.; Tecuceanu, V.; Maganu, M.; Hanganu, A.; Razus, A. C.; Buica, G. O.; Ungureanu, E. M.; Dyes Pigm. 2016, 131, 246.

15. Zhuang, X.; Zhao, W.; Zhang, F.; Cao, Y.; Liu, F.; Bi, S.; Feng, X.; Polym. Chem. 2016, 7, 4176.

16. Green, B. T.; Lee, S. T.; Panter, K. E.; Brown, D. R.; Food Chem. Toxicol. 2012, 50, 2049.

17. Cushny, A. R.; J. Exp. Med. 1896, 1, 202.

18. Brahmachari, G.; ACS Sustainable Chem. Eng. 2015, 3, 2350.

19. Jafari, A. A.; Ghadami, M.; Environ. Chem. Lett. 2016, 14, 215.

20. Dandia, A.; Parewa, V.; Kumari, S.; Bansal, S.; Sharma, A.; Green Chem. 2016, 18, 2488.

21. Dhorajiya, B. D.; Dholakiya, B. Z.; Res. Chem. Intermed. 2015, $41,277$.

22. Eskandari, K.; Karami, B.; Khodabakhshi, S.; Farahi, M.; J. Chin. Chem. Soc. 2015, 62, 473.

23. Lenardão, E. J.; Freitag, R. A.; Dabdoub, M. J.; Batista, A. C. F.; Silveira, C. D. C.; Quim. Nova 2003, 26, 123.

24. Anastas, P.; Eghbali, N.; Chem. Soc. Rev. 2010, 39, 301.

25. Anastas, P. T.; Warner, J. C.; Green Chemistry: Theory and Practice; Oxford University Press, 1998.

26. Srivastava, S.; Aggarwal, H.; Gupta, R.; Cryst. Growth Des. 2015, 15, 4110.

27. Regati, S.; He, Y.; Thimmaiah, M.; Li, P.; Xiang, S.; Chen, B.; Zhao, J. C. G.; Chem. Commun. 2013, 49, 9836.

28. Mrówczyński, R.; Nan, A.; Liebscher, J.; RSC Adv. 2014, 4, 5927.

29. Parveen, M.; Azaz, S.; Ahmad, F.; Malla, A. M.; Alam, M.; Catal. Lett. 2016, 146, 1687.

30. Dhinakaran, I.; Padmini, V.; Bhuvanesh, N.; ACS Comb. Sci. 2016, 18, 236.

31. Dumbre, D. K.; Mozammel, T.; Selvakannan, P. R.; Hamid, S. B. A.; Choudhary, V. R.; Bhargava, S. K.; J. Colloid Interface Sci. 2015, 441, 52.

32. de Paula, B. R. S.; Zampieri, D. S.; Zukerman-Schpector, J.; Tiekink; E. R. T.; Rodrigues, J. A. R.; Moran, P. J. S.; J. Braz. Chem. Soc. 2012, 23, 825.

33. Seyyedi, N.; Shirini, F.; Langarudi, M. S. N.; RSC Adv. 2016, 6, 44630 .

34. Hu, X.; Zheng, Q.; Ngwa, C.; Curr. Org. Synth. 2016, 13, 101.

35. Wach, A.; Drozdek, M.; Dudek, B.; Łątka, P.; Kuśtrowski, P.; Microporous Mesoporous Mater. 2016, 226, 433. 
36. Elhamifar, D.; Kazempoor, S.; J. Mol. Catal. A: Chem. 2016, $415,74$.

37. Isobe, K.; Hoshi, T.; Suzuki, T.; Hagiwara, H.; Mol. Diversity 2005, 9, 317.

38. Abedini, M.; Shirini, F.; Omran, J. M. A.; Seddighi, M.; Goli-Jolodar, O.; Res. Chem. Intermed. 2016, 42, 4443.

39. Bednarz, S.; Bogdal, D.; Int. J. Chem. Kinet. 2009, 41, 589.

40. Ouyang, F.; Zhou, Y.; Li, Z. M.; Hu, N.; Tao, D. J.; Korean J. Chem. Eng. 2014, 31, 1377.

41. Wang, Y.; Shang, Z. C.; Wu, T. X.; Fan, J. C.; Chen, X.; J. Mol. Catal. A: Chem. 2006, 253, 212.

42. Siddiqui, I. R.; Shamim, S.; Rai, P.; Waseem, M. A.; Srivastava, A.; Srivastava, A.; J. Heterocycl. Chem. 2015, 53, 849.

43. Mejía, S. M.; Flórez, E.; Mondragón, F.; J. Chem. Phys. 2012, 136, 144306.

44. Akerlof, G.; J. Am. Chem. Soc. 1932, 54, 4125.

45. Van Leeuwen, M. E.; Fluid Phase Equilib. 1994, 99, 1.

46. Cunha, S.; Santana, L. L. B.; Quim. Nova 2012, 35, 642.

47. Bigi, F.; Carloni, S.; Ferrari, L.; Maggi, R.; Mazzacani, A.; Sartori, G.; Tetrahedron Lett. 2001, 42, 5203.

48. Zhao, X. L.; Yang, K. F.; Zhang, Y. P.; Zhu, J.; Xu, L. W.; Chin. Chem. Lett. 2014, 25, 1141.

49. Patil, S.; Jadhav, S. D.; Deshmukh, M. B.; J. Chem. Sci. 2013, $125,851$.
50. Mobarakeh, M. I.; Saffar-Teluri, A.; Tabrizi, S. A. H.; Res. Chem. Intermed. 2015, 41, 6625.

51. Wang, X. S.; Zeng, Z. S.; Li, Y. L.; Shi, D. Q.; Tu, S. J.; Wei, X. Y.; Zong, Z. M.; Synth. Commun. 2005, 35, 1915.

52. Pourjavadi, A.; Hosseini, S. H.; Amin, S. S.; Chem. Eng. J. 2014, 247, 85.

53. Yang, Y.; Yao, H. F.; Xi, F. G.; Gao, E. Q.; J. Mol. Catal. A: Chem. 2014, 390, 198.

54. Zhao, X. L.; Yang, K. F.; Zhang, Y. P.; Zhu, J.; Xu, L. W.; Chin. Chem. Lett. 2014, 25, 1141.

55. Li, J. T.; Chen, G. F.; Wang, S. X.; He, L.; Li, T. S.; Aust. J. Chem. 2005, 58, 231.

56. Paun, C.; Barklie, J.; Goodrich, P.; Gunaratne, H. Q. N.; Mckeown, A.; Parvulescu, V. I.; Hardacre, C.; J. Mol. Catal. A: Chem. 2007, 269, 64.

57. Yadav, J. S.; Reddy, B. V. S.; Basak, A. K.; Visali, B.; Narsaiah, A. V.; Nagaiah, K.; Eur. J. Org. Chem. 2004, 2004, 546.

58. Moemeni, M. H.; Amrollahi, M. A.; Tamaddon, F.; Bulg. Chem. Commun. 2015, 47, 7 .

Submitted: September 27, 2017 Published online: December 21, 2017 